\title{
Sufentanil EC50 for endotracheal intubation with aerosol inhalation of carbonated lidocaine by ultrasonic atomizer
}

\author{
Qiaoqiao Xu+ ${ }^{\dagger}$, Zhiqiang Zhou ${ }^{\dagger}$, Ling Ai, Jieqiong Liu and Xuebi Tian ${ }^{*}$ (D)
}

\begin{abstract}
Background: Nebulized lidocaine reduced stress response for endotracheal intubation. However, the impact of novel lidocaine aerosol inhalation for intubation by ultrasonic atomizer was unclear. Hence, we designed aerosol inhalation of lidocaine by ultrasonic atomizer, to seek whether the dosage of sufentanil for intubation could be less or not.

Methods: Intravenous injection of sufentanil started at $0.5 \mu \mathrm{g} / \mathrm{kg}$, and sufentanil dosage was increased/decreased (step-size $0.05 \mu \mathrm{g} / \mathrm{kg}$ for sufentanil) using Dixon's up and down method. The observation was terminated after 8 reflexes.

Results: The EC50 and EC95 of sufentanil with lidocaine by ultrasonic atomizer for intubation were found to be $0.232 \mu \mathrm{g} / \mathrm{kg}$ ( $95 \% \mathrm{Cl}: 0.187-0.270 \mu \mathrm{g} / \mathrm{kg}$ ) and $0.447 \mu \mathrm{g} / \mathrm{kg}$ (95\% Cl: $0.364-0.703 \mu \mathrm{g} / \mathrm{kg}) .55 .88 \%$ out of 34 patients showed hemodynamic index change $<20 \%$ of baseline during intubation.

Conclusion: Aerosol inhalation of lidocaine by ultrasonic atomizer reduced the dosage of sufentanil for endotracheal intubation. Lidocaine inhalation by ultrasonic atomizer for airway anesthesia with minimal dosage of sufentanil could be recommended, particularly in patients who need more stable hemodynamic changes or spontaneous respiration.
\end{abstract}

Trial registration: Chinese Registry of Central Trial, ChiCTR-IOR-17014198.

Registered 28 December 2017.

Keywords: Aerosol inhalation, Lidocaine, Endotracheal intubation, EC50, Sufentanil

\section{Background}

Endotracheal intubation was a routine procedure in clinical general anesthesia. But the placement of laryngoscope and endotracheal tube irritated the glottis and trachea leading to the reflex sympathetic reaction [1]. There were several ways to reduce the stress response and attenuate the adverse hemodynamics fluctuations

\footnotetext{
* Correspondence: tianxb@hust.edu.cn

${ }^{\dagger}$ The authors consider that Qiaoqiao Xu and Zhiqiang Zhou should be regarded as co-first authors.

Department of Anesthesiology, Tongji Hospital, Tongji Medical College, Huazhong University of Science and Technology, 1095 Jie Fang Avenue, Wuhan 430030, Hubei, China
}

during laryngoscopy placement and intubation, such as enhancing the depth of anesthesia with high dosage of opioids, airway surface anesthesia with local anesthetic, or negative inotropic drugs and antihypertensive drugs to prevent the adverse cardiovascular events. High dosage of opioids caused side effects like respiratory depression, hemodynamic fluctuation and intestinal peristalsis decrease [2]. Cardiovascular drugs were high risk factors for cardiovascular and cerebrovascular diseases in elder $[3,4]$. Therefore, slowly anesthesia induction, gently intubation and low-opioid anesthesia were suggested in patients, particularly with various complications.

C C The Author(s). 2021 Open Access This article is licensed under a Creative Commons Attribution 4.0 International License, which permits use, sharing, adaptation, distribution and reproduction in any medium or format, as long as you give appropriate credit to the original author(s) and the source, provide a link to the Creative Commons licence, and indicate if changes were made. The images or other third party material in this article are included in the article's Creative Commons licence, unless indicated otherwise in a credit line to the material. If material is not included in the article's Creative Commons licence and your intended use is not permitted by statutory regulation or exceeds the permitted use, you will need to obtain permission directly from the copyright holder. To view a copy of this licence, visit http://creativecommons.org/licenses/by/4.0/ The Creative Commons Public Domain Dedication waiver (http://creativecommons.org/publicdomain/zero/1.0/) applies to the data made available in this article, unless otherwise stated in a credit line to the data. 
However, endotracheal intubation could not be carried out with no stress response under opioid-free anesthesia. Lidocaine was often used for oral airway surface anesthesia. Topical lidocaine surface anesthesia combined with minimal opioid was recommended in awake tracheal intubation [5]. Both 2 and $4 \%$ lidocaine administered topically could provide clinically acceptable intubating conditions for awake intubation [6,7]. Airway lidocaine had a rapid onset of action (1-5 $\mathrm{min})$ and intermediate duration of efficacy $(10-15 \mathrm{~min})$ [8]. The traditional administration was just spray lidocaine directly onto part of airway mucosa, the uncomfortable, hypertension or heart rate increase in patients were still existed. The lidocaine inhalation for airway anesthesia by ultrasonic atomizer was easy and valid. Evidence showed inhalation of lidocaine attenuated the response to airway irritation with lower plasma concentrations [9].

The lidocaine inhalation by ultrasonic atomizer combined with minimal opioid could be optimized strategic for the elderly patients. Meanwhile, it was practical for these special patients with difficult airway, who need less opioid to maintain spontaneous respiration. Moreover, these patients were suitable to receive lidocaine inhalation, who were required spontaneous respiration by laryngeal mask with low-opioid anesthesia, like thoracoscopic surgery. However, the effective concentration of the minimal opioid was indistinct. Therefore, we speculated that aerosol inhalation of carbonated lidocaine could reduce the amount of sufentanil used. And, in this study, we aimed to investigate the sufentanil EC50 for endotracheal intubation with inhalation lidocaine by ultrasonic atomizer.

\section{Methods}

\section{Inclusion and exclusion criteria}

Our study was a single centre, prospective, double-blind clinical trial. The EC50 of sufentanil for endotracheal intubation was estimated with aerosol inhalation of nebulized lidocaine.

Testing was performed in Tongji Hospital, Tongji Medical College, Huazhong University of Science and Technology, 1095 Jie Fang Avenue, Wuhan 430,030, Hubei, China. Patients, American Society of Anesthesiology (ASA) physical status I or II, age 18-70 years, $\mathrm{BMI}<25$ without difficult airway, were scheduled to undergo elective surgery (ophthalmology or gynecology). The hepatic function, renal function, and ECG results were normal in these patients. With no liver and renal dysfunction and no cardiovascular disease. Patients eventually enrolled were $23-63$ years old. The one was excluded with a history of local anesthetic allergy, oral and otolaryngologic lesions or surgical history, cardiovascular disease and COPD (chronic obstructive pulmonary disease). Patients in other clinical trials or researchers were excluded. All patients were given informed consent, and signed the informed consent form. They were evaluated preoperatively. A complete history of present and previous illness was taken, general physical examination and systemic examination were conducted to assess the fitness for the proposed procedure. Premedication was not prescribed to any patients.

\section{Study protocol}

The Dixon's up and down method was adopted [10], and intravenous injection of sufentanil starting at $0.5 \mu \mathrm{g} /$ $\mathrm{kg}$. Then sufentanil dosages were increased/decreased (step-size $0.05 \mu \mathrm{g} / \mathrm{kg}$ for sufentanil) using Dixon's up and down method in the next patient, depending upon the previous patient's response within $3 \mathrm{~min}$ after intubation. If the hemodynamic index change $<20 \%$ of baseline during endotracheal intubation, the sufentanil dosage would be decreased $0.05 \mu \mathrm{g} / \mathrm{kg}$ in next patients. If the hemodynamic index change $>20 \%$ of baseline during endotracheal intubation, the sufentanil dosage would be increased $0.05 \mu \mathrm{g} / \mathrm{kg}$ in next patients. The decrease to increase point, or the increase to decrease point of sufentanil dosage were as one of the reflexes. The observation was terminated after 8 reflexes. Endotracheal intubation was performed and scored by the same attending physician.

Forty patients were screened for eligibility, monitored by blood pressure (BP), pulse $(\mathrm{P})$, electrocardiogram (ECG), $\mathrm{SpO}_{2}$, Nacrotrend values and muscle relaxant monitoring (train of four, TOF) during perioperative period. Thirty-six eligible patients were recruited in the study, 19 males and 17 females. After intravenous cannulation, Allen's test was performed routinely before radial arterial artery cannulation, to make sure the puncture could be carried out without severe complications. The radial artery puncture and catheter under local anesthesia were established for arterial blood pressure $(A B P)$ monitoring. Aerosol inhalation of $4 \mathrm{mg} / \mathrm{kg}$ carbonated lidocaine by the ultrasonic atomizer (YUWELL, 402B) was accomplished, prior to induction of anesthesia with a special atomizing nozzle. The atomizing nozzle was in the patient's mouth airtightly. Waited 5 min for lidocaine to take effect. Then intravenous of anesthesia induction was achieved with propofol TCI (according to Nacrotrend monitoring anesthesia depth), rocuronium $0.9 \mathrm{mg} / \mathrm{kg}$, and sufentanil. Until Nacrotrend value to 40 and TOF value to 0 , endotracheal intubation was implemented by the experienced anesthesiologist using standard Macintosh blade laryngoscope. After that during maintenance of anesthesia, propofol and remifentanil were pumped continuously, and rocuronium was injected intermittently. 
The time points needed record were those: prior to the aerosol lidocaine inhalation (T0), after the aerosol lidocaine inhalation (T1), after intravenous induction (T2), at the time point of endotracheal intubation (T3), and $1 \mathrm{~min}$ (T4), $2 \mathrm{~min}$ (T5), $3 \mathrm{~min}$ (T6) after endotracheal intubation. $\mathrm{HR}, \mathrm{P}, \mathrm{BP}, \mathrm{SpO}_{2}$, and Nacrotrend values were collected.

\section{Blinding}

The observations of response to endotracheal intubation were recorded by an independent anesthetist. Monitor screen was applied between the anesthetist who was responsible for observations and the anesthetist who managed endotracheal intubation. The patients and the anesthetists for intubation were not aware of the dosage of sufentanil. The sufentanil administered by another superior anesthesiologist, who calculated the dosage of sufentanil according the previous patient's response within $3 \mathrm{~min}$ after intubation.

\section{Outcome measures}

The primary outcome was effective concentration (EC50) of sufentanil causing "hemodynamic index change $<20 \%$ of baseline" during endotracheal intubation in $50 \%$ of study population. Adverse events to circulation (HR, BP) were noted as secondary outcomes.

\section{Statistical analysis}

Statistical analysis was performed using Excel 2007 (Microsoft, Redmond, WA, USA) and SPSS version 15.0 software (IBM, Armonk, NY, USA). Patients' characteristics were presented as mean (SD) or absolute numbers (percentages). Continuous variables were analyzed by $\mathrm{t}$ test and categorical variables were analyzed by $x^{2}$ test. Sufentanil EC50 was calculated by modified Dixon's up and down method (MDUDM) [11]. The mean of midpoint of all unsuccessful/successful pairs was used to determine EC50 using Dixon's up and down method. Dose-response curve for EC50 with 95\% confidence intervals $(\mathrm{CI})$ were determined using probit regression analysis. Sample size was calculated based on the fact that a minimum of 8 crossover pairs were required for the analysis. The Pearson correlation analysis was used to study the correlation between patient's characteristics and response to endotracheal intubation.

\section{Results}

We assessed 40 patients for eligibility. Thirty-six eligible patients were recruited in the study (Fig. 1). Two patients were excluded from the study because of the poor coordinate in lidocaine inhalation. Demographic characteristics of study population were presented in Table 1.

The EC50 and EC95 of sufentanil with aerosol inhalation of lidocaine for endotracheal intubation were found to be $0.232 \mu \mathrm{g} / \mathrm{kg}$ (95\% CI: $0.187-0.270 \mu \mathrm{g} / \mathrm{kg}$ ) and $0.447 \mu \mathrm{g} / \mathrm{kg}$ (95\% CI: 0.364-0.703 $\mu \mathrm{g} / \mathrm{kg})$. The intravenous dosage of sufentanil-response data obtained by the up-down method (Fig. 2). The concentration of sufentanil and the response curve to endotracheal intubation were presented in Fig. 3.

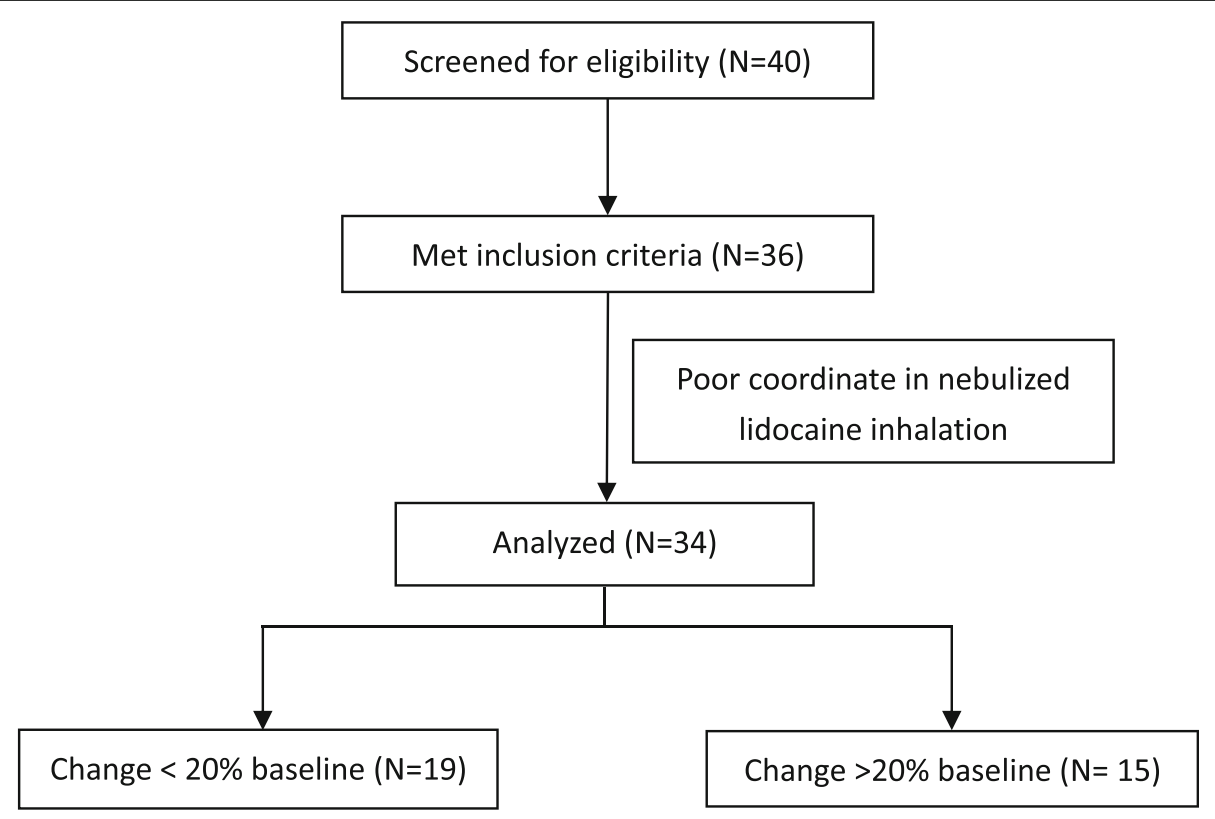

Fig. 1 Study flow diagram 
Table 1 Demographic data of study population

\begin{tabular}{ll}
\hline Male/Female & $\mathbf{1 6 / 1 8}$ \\
\hline ASA I/II & $29 / 5$ \\
Age (y) & $47.35 \pm 11.87$ \\
Height (cm) & $162.65 \pm 7.08$ \\
Bodyweight (kg) & $58.15 \pm 6.76$ \\
BMl & $22.00 \pm 2.32$ \\
Mallampati Grade I/II & $31 / 3$ \\
\hline
\end{tabular}

Values are presented as mean \pm SD or absolute numbers

$55.88 \%$ out of 34 patients showed hemodynamic index change $<20 \%$ of baseline during endotracheal intubation. Fifteen patients (44.12\%) showed hemodynamic index change $>20 \%$ of baseline during endotracheal intubation. None of the patient showed laryngospasm, local anesthetic allergy, sore throat, or hoarseness. The amplitude of hemodynamic indexes (HR and BP) variation for each patient were shown in Fig. 4.

\section{Discussion}

Therapeutic uses of nebulized lidocaine for the upper airway were verified. Evidences showed the therapeutic uses of nebulized lidocaine in the treatment of intractable cough, asthma and reactive airway dysfunction syndrome [12-14]. Nielson et al. prospectively evaluated the effect of topical lidocaine in children, and they found lidocaine exaggerated findings associated with laryngomalacia that resulted in a higher laryngomalacia score [15]. Inhalation of lidocaine attenuated the response to airway irritation with plasma concentrations lower than those systemic administration [9, 16]. Topical lidocaine reduced upper airway reflexes (cough, mechanoreceptor reflexes, and genioglossus muscle activity) and impaired the arousal response [17-19].

Koirala $S$ reported a case about topical anesthesia of the vocal cords by nebulized lidocaine inhalation, to facilitate fiberoptic nasotracheal intubation in a head-size parotid tumor patient, emphasizing the possibility of fiberoptic intubation in a sedated yet spontaneously breathing patient by allowing inhalation of nebulized lidocaine [20]. However, only lidocaine through ultrasonic nebulizer may not provide acceptable conditions for awake fiberoptic bronchoscopy [21]. And then, nebulized lidocaine combined with fentanyl, as a premedication to general anesthesia, was a recommended implementation in spontaneously breathing patients undergoing rigid bronchoscopy [22]. It was also recommended the cautious use of minimal sedation and analgesia, and combined encouraged appropriate local anesthetic topicalization in awake tracheal intubation [5]. Opioids, administered as bolus or continuous infusion at the reported dosages, appeared safe and effective with some advantage in reducing coughing and gag reflex [23]. A minimal opioids technique could be safely and effectively performed to reduce patient anxiety, discomfort, and increased patient co-operation level [24, 25].

There were several topical lidocaine administration strategies for upper airway as follows [26]: the patient gargled $2 \%$ viscous lidocaine while positioned upright, administered using a small disposable drinking cup; an alternative to the previous step involved the use of lidocaine paste; some clinicians used lidocaine-soaked pledgets as part of the procedure; 4\% lidocaine was administrated to oropharyngeal and glottic structures

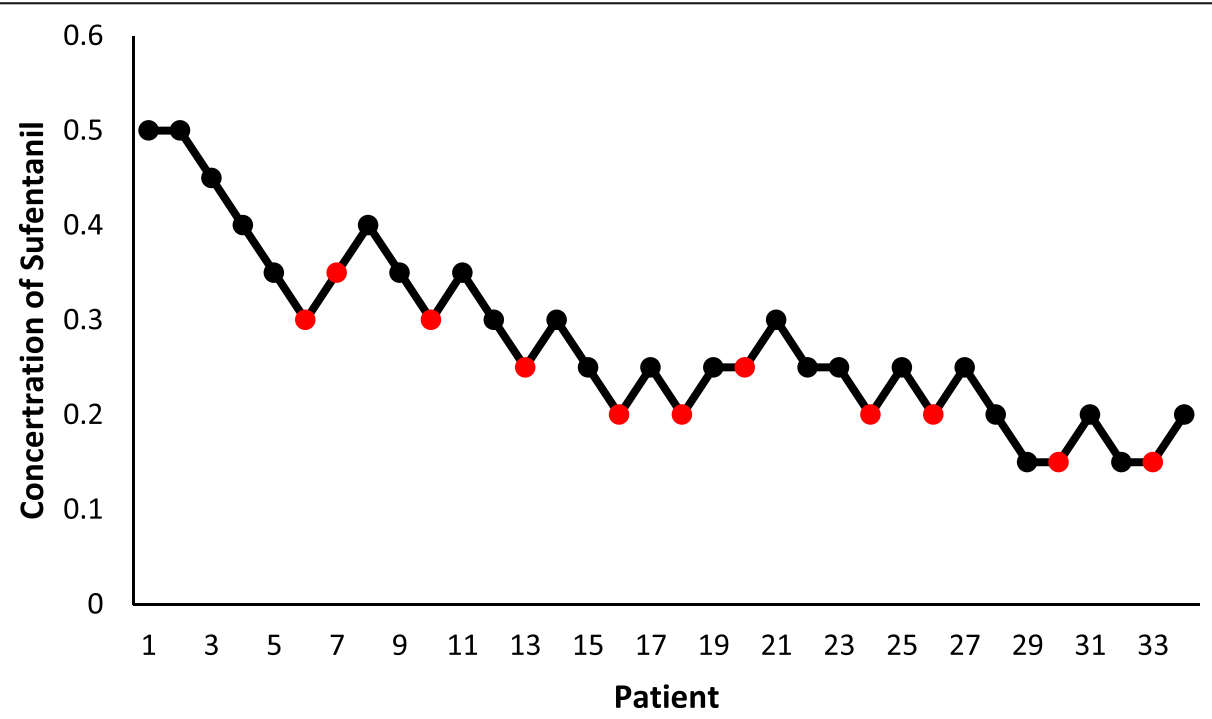

Fig. 2 The 34 consecutive patients were attempted, and the concentration of sufentanil was determined according to the Dixon's up-and-down method 


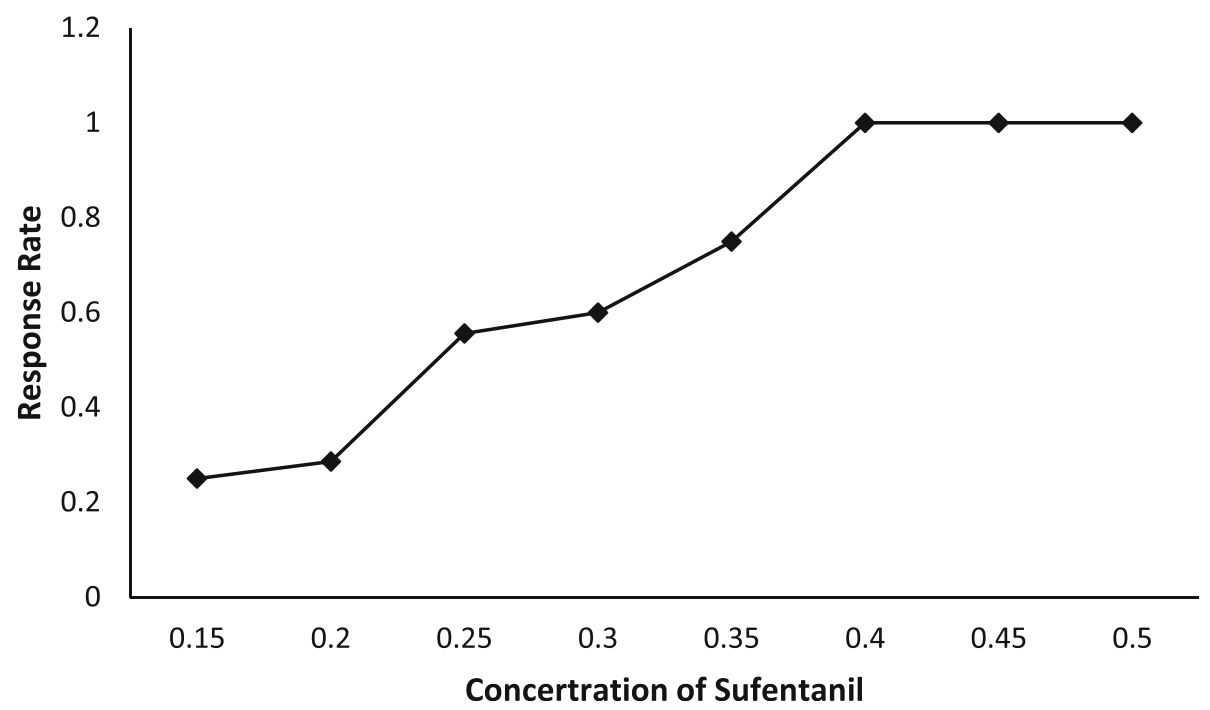

Fig. 3 Concentration response curve of sufentanil and the respective reactions to endotracheal intubation was plotted from probit analysis

using an oxygen-driven power sprayer; $4 \%$ lidocaine was administered through the airway guide using special device; the translaryngeal block numbed the larynx and trachea with injected lidocaine through the cricothyroid membrane, inducing coughing that scattered the local anesthetic; nerve blocks by lidocaine injection subdermal for superior laryngeal nerve and recurrent laryngeal nerve block. The effectivity and safety of all these topical lidocaine administration strategies needed to be sure. Nebulization of lidocaine by a device for intermittent positive pressure breathing (IPPB $280 \mathrm{mg}$ ) or by an ultrasonic $(400 \mathrm{mg})$, nebulizer was reported as a topical anesthetic for the airway, with favorable results [27]. And aerosol inhalation of nebulized lidocaine local anesthesia by atomization device could provide a more comprehensive, convenient and fast way for OralLaryngo-Tracheal omnibearing mucosal contact before intubation.

For the effect on regional deposition, the significant of particle aerodynamic diameter and inhalation maneuver needed to be concerned [28]. Large particles $(5-15 \mu \mathrm{m})$ were mainly deposited in the upper airways and trachea, intermediate-sized particles $(3-5 \mu \mathrm{m})$ were tendency deposited in the bronchi and bronchioles, and small particles $(\leq 3 \mu \mathrm{m})$ were flowed into the alveoli [29]. The aerosol characteristics were closely related to the device of atomizer, which depended on the design of pressure swirl, airblast and ultrasonic atomizers [30]. The

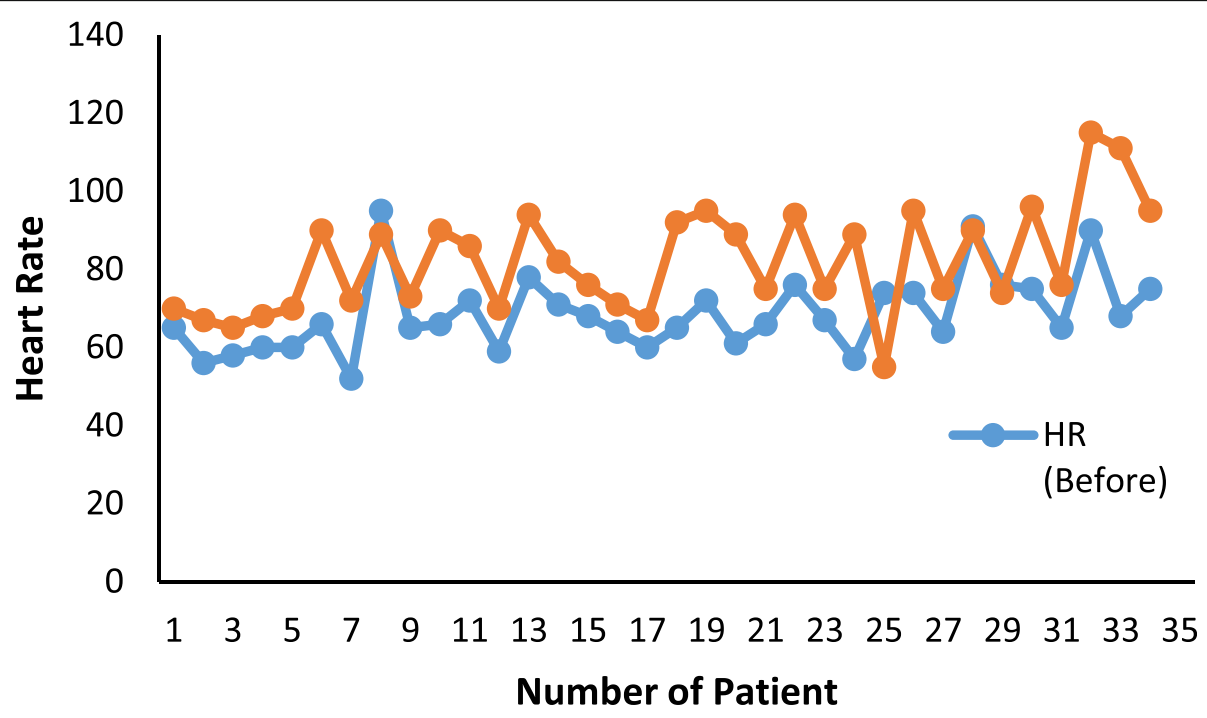

Fig. 4 The heart rate values of 34 patients before and after endotracheal intubation were shown 
ultrasonic atomizers operated at different frequencies, which were well with the median droplet size [31]. The piezoelectric part of the ultrasonic atomizer (YUWELL, 402B) produced 35\% carbonated lidocaine particle sizes above $5.0 \mu \mathrm{m}$, which providing good surface analgesic effect in upper airway and trachea. The maximum rate of aerosol inhalation was more than $3.0 \mathrm{ml} / \mathrm{min}$. And it just took $10 \mathrm{~min}$ to prepare and finish the whole process of inhalation.

Aerosol inhalation of nebulized lidocaine local anesthesia caused fewer trauma to the oropharyngeal and laryngeal tissues, avoided the risk of injection into vessels compared with nerve blocks, and possibly decreased the risk of systemic toxicity [32]. Lidocaine plasma concentrations below $6.0 \mu \mathrm{g} / \mathrm{ml}$ were considered safe. Given the lidocaine was administered by infiltration, the occurrence of neurological symptoms in healthy volunteers was about $8 \mathrm{mg} / \mathrm{kg}$, corresponding to a plasma value of about $15 \mu \mathrm{g} / \mathrm{ml}$ [33]. The lidocaine plasma concentration was $0.7 \pm 0.3 \mu \mathrm{g} / \mathrm{ml}$ when inhalation of lidocaine was $5 \mathrm{mg} / \mathrm{kg}$ [34]. In our study, the time of atomization inhalation lasted $5 \mathrm{~min}$, and the dose of lidocaine was about $300 \mathrm{mg}$, it was safe as lidocaine plasma concentrations was far below $6.0 \mu \mathrm{g} / \mathrm{ml}$.

In addition, we used carbonated lidocaine for inhalation in our study. The reason was that surface anesthetic effect of carbonated lidocaine was 4 times more than lidocaine hydrochloride [35]. Because the carbon dioxide released following permeation could produce local vasodilatation which increased the rate of absorption. In addition, as the carbon dioxide released following permeation, there was a resultant increase in $\mathrm{pH}$, which augmented formation of free base. In that way, the local anesthetic was readily diffused across biological membranes, and the neural and vascular uptake were facilitated [36].

By Adamus $M$, excellent intubation conditions were observed in 28,41 and $54 \%$, while poor conditions were present in 31,7 and $3 \%$ of patients each receiving sufentanil $0.2,0.3$ or $0.4 \mu \mathrm{g} / \mathrm{kg}$ respectively. Therefore, sufentanil $(0.3-0.4 \mu \mathrm{g} / \mathrm{kg}$ in combination with propofol $(2 \mathrm{mg} /$ $\mathrm{kg}$ ) provided clinically acceptable intubating conditions in $93-97 \%$ patients [37]. In our study, inhalation aerosol lidocaine was accomplished prior to induction of anesthesia. The intravenous of anesthesia was achieved with propofol, rocuronium $0.9 \mathrm{mg} / \mathrm{kg}$, and combined with different adjusting dosage of sufentanil according to the reaction for intubation starting at $0.5 \mu \mathrm{g} / \mathrm{kg}$. However, it was indicated that inhalation aerosol lidocaine reduced the amount of sufentanil needed for endotracheal intubation, and the EC50 sufentanil with aerosol lidocaine was only found to be $0.232 \mu \mathrm{g} / \mathrm{kg}$. Twenty-three $(55.88 \%)$ out of the all 34 patients showed hemodynamic index change $<20 \%$ of baseline during endotracheal intubation. It signified that combined with inhalation aerosol lidocaine for endotracheal intubation reduced the dosage of opioids, enhanced hemodynamic stability, and provided better intubation conditions.

A major limitation of this study was that each patient routinely received lidocaine for a fixed period of time ( 5 min) with aerosol inhalation, not according to the patient's individual differences, which might impact the results. Moreover, only 35\% particles of aerosol inhalation were the ideal size for the upper airways. A more efficient method or medical facilities of aerosol inhalation for upper airway surface anesthesia would be still worthy of further exploration.

\section{Conclusion}

The advantages in carbonated lidocaine inhalation by ultrasonic atomizer for airway anesthesia were revealed in our study. Inhalation of aerosol carbonated lidocaine was expected to reduce the amount of sufentanil obviously, and then provided stable hemodynamic change which avoiding or reducing the usage of cardiovascular drugs. Therefore, for the patients with cardiovascular and cerebrovascular diseases, especially in elders need low-opioid, the aerosol inhalation of lidocaine by the ultrasonic atomizer before endotracheal intubation was the key step in anesthesia induction. The patients, who needed awake tracheal intubation as difficult airway, were provided a more effective and mucosal all-sided airway anesthesia technique with lower sufentanil dosage to keep spontaneous respiration. And in some natural airway video assisted thoracoscopic surgery in ERAS (Enhanced Recovery After Surgery), which reserved the spontaneous respiration without intubation, the patient was prepared and managed the intubation in case. Under the spontaneous respiration, the pulmonary tissue of the operation side could only be flat under the atmospheric pressure. The aerosol inhalation of lidocaine by the ultrasonic atomizer was a suitable method to prepare the airway for intubation in these cases as well, which required the minimal amount of sufentanil to make sure the spontaneous respiration recovery as soon as possible, and the spontaneous respiration was maintained in the whole surgery. However, the intubation could be implemented as prearranged under upper airway surface anesthesia by inhalation aerosol lidocaine at any emergency situation. Hence, there were more clinical prospects with aerosol inhalation of carbonated lidocaine by ultrasonic atomizer, such as awake endotracheal intubation, and so on.

\section{Abbreviations}

ABP: Arterial blood pressure; ASA: American society of anesthesiology; BP: Blood pressure; Cl: Confidence interval; COPD: Chronic obstructive pulmonary disease; EC50: Concentration for $50 \%$ of maximal effect; 
ECG: Electrocardiogram; HR: Heart rate; P: Pulse; $\mathrm{SpO}_{2}$ : Pulse oxygen saturation; TCl: Target control infusion; TOF: Train of four; ERAS: Enhanced recovery after surgery

\section{Acknowledgements}

Not applicable.

\section{Authors' contributions}

$\mathrm{QQX}$ and ZQZ were the co-first authors of this article, responsible for the experiment and data analysis. LA was responsible for the patient data collection. JQL took part in revising this article, and gave constructive advices to this study. XBT, the corresponding authors of this article in charge of the project, was responsible for the expenses, and were involved in the design of the project and modified the manuscript. All authors read and approved the final manuscript.

\section{Funding}

This work was supported by the National Natural Science Foundation of China (81974170 to corresponding author Xuebi Tian, and 81600938 to first author Qiaoqiao Xu). The funding body was not involved in the design, preparation, or writing of this manuscript.

\section{Availability of data and materials}

The data of this article was available from the corresponding author. The email address of the corresponding author was tianxb@hust.edu.cn.

\section{Declarations}

\section{Ethics approval and consent to participate}

The study was conducted accordance to the principles of Declaration of Helsinki. After obtaining institute ethical committee approval (referral number S308, dated Nov 22, 2017) at Tongji hospital, Tongji Medical College, Huazhong Science and Technology University, the study was registered prospectively with Chinese Registry of Central Trial (ChiCTR-IOR-17014198) before the beginning of patient enrolment, and we obtained the informed consent which was written by all participants in the study.

\section{Consent for publication}

Not applicable.

\section{Competing interests}

The authors declared that they had no competing interests.

Received: 3 November 2020 Accepted: 5 May 2021

Published online: 12 May 2021

\section{References}

1. Sengupta S, Swaika S, Banerjee SS, Sheet J, Mandal A, Bisui B. Successful emergency airway management in a case of removal of foreign body bronchus in a pediatric patient. Anesth Essays Res. 2014;8:250-2.

2. Kim SH, Oh CS, Lee SJ. Efficacy of palonosetron and ramosetron on postoperative nausea and vomiting related to intravenous patientcontrolled analgesia with opioids after gynecological laparoscopic surgery (double-blinded prospective randomized controlled trial). J Anesth. 2015; 29(4):585-92. https://doi.org/10.1007/s00540-015-1981-4.

3. Bas M, Greve J, Strassen U, Khosravani F, Hoffmann TK, Kojda G. Angioedema induced by cardiovascular drugs: new players join old friends. Allergy. 2015;70(10):1196-200. https://doi.org/10.1111/all.12680.

4. Westerbotn M, Aguero-Torres H, Fastbom J, Hilleras P. A population-based study on well-being in the very old: the role of cardiovascular diseases and drugs. Arch Gerontol Geriatr. 2005;40(3):287-97. https://doi.org/10.1016/j.a rchger.2004.09.005

5. El-Boghdadly K, Ahmad I. Difficult airway society awake tracheal intubation guidelines G: the safety of topical lidocaine for awake tracheal intubation: a reply. Anaesthesia. 2020;75(9):1260-1. https://doi.org/10.1111/anae.15101.

6. Dreher M, Cornelissen CG, Reddemann MA, Muller A, Hubel C, Muller T. Nebulized versus standard local application of lidocaine during flexible bronchoscopy: a randomized controlled trial. Respiration. 2016;92(4):266-73. https://doi.org/10.1159/000449135.

7. Lim KG, Rank MA, Hahn PY, Keogh KA, Morgenthaler TI, Olson EJ. Long-term safety of nebulized lidocaine for adults with difficult-to-control chronic cough: a case series. Chest. 2013;143(4):1060-5. https://doi.org/10.1378/ chest.12-1533.

8. Ehsan Z, Mahmoud M, Shott SR, Amin RS, Ishman SL. The effects of anesthesia and opioids on the upper airway: a systematic review. Laryngoscope. 2016;126(1):270-84. https://doi.org/10.1002/lary.25399.

9. Groeben $\mathrm{H}$. Strategies in the patient with compromised respiratory function. Best Pract Res Clin Anaesthesiol. 2004;18(4):579-94. https://doi.org/10.1016/j. bpa.2004.05.013.

10. Dixon WJ. Staircase bioassay: the up-and-down method. Neurosci Biobehav Rev. 1991;15(1):47-50. https://doi.org/10.1016/S0149-7634(05)80090-9.

11. Oh AY, Cho SJ, Seo KS, Ryu JH, Han SH, Hwang JW. Dose of rocuronium for rapid tracheal intubation following remifentanil $2 \mathrm{m \mu g} / \mathrm{kg}$ and propofol 2 mg/kg. Eur J Anaesthesiol. 2013;30(9):550-5. https://doi.org/10.1097/EJA. Ob013e3283622ba0.

12. Slaton RM, Thomas RH, Mbathi JW. Evidence for therapeutic uses of nebulized lidocaine in the treatment of intractable cough and asthma. Ann Pharmacother. 2013;47(4):578-85. https://doi.org/10.1345/aph.1R573.

13. Ozyigit LP, Erer A, Okumus G, Cagatay T, Kiyan E, Erkan F. Nebulized lidocaine as an alternative therapy for reactive airway dysfunction syndrome. Turk Thorac J. 2016;17(2):82-3. https://doi.org/10.5578/ttj.17.2.017.

14. Truesdale K, Jurdi A. Nebulized lidocaine in the treatment of intractable cough. Am J Hosp Palliat Care. 2013;30(6):587-9. https://doi.org/10.1177/104 9909112458577.

15. Nielson DW, Ku PL, Egger M. Topical lidocaine exaggerates laryngomalacia during flexible bronchoscopy. Am J Respir Crit Care Med 2000; 161: 147151, 1, DOl: https://doi.org/10.1164/ajrccm.161.1.9811043.

16. Arslan IB, Kose I, Ciger E, Demirhan E, Gumussoy M, Cukurova I. Does topical anesthesia using aerosolized lidocaine inhibit the superior laryngeal nerve reflex? Otolaryngol Head Neck Surg. 2013;149(3):466-72. https://doi.org/1 0.1177/0194599813495372.

17. Antoniades N, Worsnop C. Topical lidocaine through the bronchoscope reduces cough rate during bronchoscopy. Respirology. 2009;14(6):873-6. https://doi.org/10.1111/j.1440-1843.2009.01587.x.

18. Berry RB, Kouchi KG, Bower JL, Light RW. Effect of upper airway anesthesia on obstructive sleep apnea. Am J Respir Crit Care Med. 1995;151(6):1857-61. https://doi.org/10.1164/ajrccm.151.6.7767531.

19. Berry RB, McNellis Ml, Kouchi K, Light RW. Upper airway anesthesia reduces phasic genioglossus activity during sleep apnea. Am J Respir Crit Care Med. 1997;156(1):127-32. https://doi.org/10.1164/ajrccm.156.1. 9608037.

20. Koirala S, Tripathi M, Subedi A, Bhattarai B. Topical anaesthesia of the vocal cords by nebulized lignocaine inhalation to facilitate fibreoptic nasotracheal intubation in a head-size parotid tumour patient. JNMA J Nepal Med Assoc. 2011:51(181):34-6.

21. Gupta B, Kohli S, Farooque K, Jalwal G, Gupta D, Sinha S, et al. Topical airway anesthesia for awake fiberoptic intubation: comparison between airway nerve blocks and nebulized lignocaine by ultrasonic nebulizer. Saudi J Anaesth. 2014:8:S15-9.

22. Moustafa MA. Nebulized lidocaine alone or combined with fentanyl as a premedication to general anesthesia in spontaneously breathing pediatric patients undergoing rigid bronchoscopy. Paediatr Anaesth. 2013;23(5):42934. https://doi.org/10.1111/pan.12081.

23. Cabrini L, Baiardo Redaelli M, Ball L, Filippini M, Fominskiy E, Pintaudi M, et al. Awake fiberoptic intubation protocols in the operating room for anticipated difficult airway: a systematic review and meta-analysis of randomized controlled trials. Anesth Analg. 2019;128(5):971-80. https://doi. org/10.1213/ANE.0000000000004087.

24. El-Boghdadly K, Onwochei DN, Cuddihy J, Ahmad I. A prospective cohort study of awake fibreoptic intubation practice at a tertiary Centre. Anaesthesia. 2017;72(6):694-703. https://doi.org/10.1111/anae.13844.

25. Law JA, Morris IR, Brousseau PA, de la Ronde S, Milne AD. The incidence, success rate, and complications of awake tracheal intubation in 1,554 patients over 12 years: an historical cohort study. Can J Anaesth. 2015;62(7): 736-44. https://doi.org/10.1007/s12630-015-0387-y.

26. Doyle DJ. Airway anesthesia: theory and practice. Anesthesiol Clin. 2015 33(2):291-304. https://doi.org/10.1016/j.anclin.2015.02.013.

27. Chinn WM, Zavala DC, Ambre J. Plasma levels of lidocaine following nebulized aerosol administration. Chest. 1977;71(3):346-8. https://doi.org/1 0.1378/chest.71.3.346.

28. Darquenne C, Fleming JS, Katz I, Martin AR, Schroeter J, Usmani OS, et al. Bridging the gap between science and clinical efficacy: physiology, imaging, 
and modeling of aerosols in the lung. J Aerosol Med Pulm Drug Deliv. 2016; 29(2):107-26. https://doi.org/10.1089/jamp.2015.1270.

29. O'Callaghan C, Barry PW. The science of nebulised drug delivery. Thorax. 1997;52(Supplement 2):S31-44. https://doi.org/10.1136/thx.52.2008.S31.

30. Godavarthi V, Dhivyaraja K, Sujith RI, Panchagnula MV. Analysis and classification of droplet characteristics from atomizers using multifractal analysis. Sci Rep. 2019;9(1):16218. https://doi.org/10.1038/s41598-019-52596-6.

31. Kooij S, Astefanei A, Corthals GL, Bonn D. Size distributions of droplets produced by ultrasonic nebulizers. Sci Rep. 2019;9(1):6128. https://doi.org/1 0.1038/s41598-019-42599-8.

32. Gupta B, Kohli S, Farooque K, Jalwal G, Gupta D, Sinha S, et al. Topical airway anesthesia for awake fiberoptic intubation: comparison between airway nerve blocks and nebulized lignocaine by ultrasonic nebulizer. Saudi J Anaesth. 2014;8:S15-9.

33. Beaussier M, Delbos A, Maurice-Szamburski A, Ecoffey C, Mercadal L. Perioperative use of intravenous lidocaine. Drugs. 2018;78(12):1229-46. https://doi.org/10.1007/s40265-018-0955-x.

34. Groeben H, Silvanus MT, Beste M, Peters J. Combined lidocaine and salbutamol inhalation for airway anesthesia markedly protects against reflex bronchoconstriction. Chest. 2000;118(2):509-15. https://doi.org/10.1378/ chest.118.2.509.

35. Bromage PR. A comparison of the hydrochloride and carbon dioxide salts of lidocaine and prilocaine in epidural analgesia. Acta Anaesthesiol Scand Suppl. 1965;16:55-69. https://doi.org/10.1111/j.1399-6576.1965.tb00523.x.

36. Sukhani R, Winnie AP. Clinical pharmacokinetics of carbonated local anesthetics. II: Interscalene brachial block model. Anesth Analg. 1987;66(12): $1245-50$.

37. Adamus M, Koutna J, Gabrhelik T, Zapletalova J. Tracheal intubation without muscle relaxant--the impact of different sufentanil doses on the quality of intubating conditions: a prospective study. Cas Lek Cesk. 2008;147:96-101.

\section{Publisher's Note}

Springer Nature remains neutral with regard to jurisdictional claims in published maps and institutional affiliations.

Ready to submit your research? Choose BMC and benefit from:

- fast, convenient online submission

- thorough peer review by experienced researchers in your field

- rapid publication on acceptance

- support for research data, including large and complex data types

- gold Open Access which fosters wider collaboration and increased citations

- maximum visibility for your research: over $100 \mathrm{M}$ website views per year

At $\mathrm{BMC}$, research is always in progress.

Learn more biomedcentral.com/submissions 